\title{
A new form of community hospital service for the elderly
}

\author{
D L BEALES
}

The implications of the Short Report ${ }^{1}$ on medical education are slowly being appreciated. The main problem of a distorted career structure and surfeit of junior hospital staff has existed for many years, whereas mandatory training for general practice $^{2}$ and the increasing competition for three-year vocational training posts are relatively recent phenomena. The Short Report recommends that the hospital practitioner grade should be fostered, but there is much misgiving about whether the main recommendation, which would mean a large increase in consultant posts, can be in the long-term interest of the Health Service. Perhaps a new partnership between hospital practitioner and consultant might be a workable solution to this overloaded career ladder.

For vocationally trained general practitioners the pressure for practice vacancies will become more intense as the numbers entering such schemes increase in parallel with the growing output from medical schools. It would therefore seem logical for doctors in vocational training to expand a special interest to a registrar equivalent or hospital practitioner level. This would be particularly appropriate in specialties where patients' psychological and social requirements need to be assessed and where the general practitioner's special skills and knowledge relating to the community may be used to the full. This paper describes a service to the elderly where co-operation between hospital and consultant has led to considerably improved efficiency and a service able to respond to the patients' needs in a defined community.

In Cirencester the general practitioners take, as hospital practitioner or clinical assistant, an intermediate role as registrar equivalent at the Memorial and Querns Hospitals. These two hospitals cover a population of about 45000 with $18 \%$ aged over 65 and $7 \%$ over 75 . The nearest district general hospital is 16 miles away, and Cirencester is the market town for the predominantly rural area. The Memorial Hospital, with 62 beds, has a complement of three SHOs, part of the general practitioner vocational training scheme. Though the beds are consultantdesignated, all the work at registrar level is carried out by general practitioners. This linkage of general practitioners in all specialties means that close relations are maintained between consultants, general practitioners, and SHOs with benefit to all. When the SHOs move into the community to do their trainee year they have already begun to form a liaison between the hospital and the local community.

\section{Policy}

At the Querns Geriatric Hospital, with 68 beds, built to an Oxford design in 1975, there are two two-person teams of GPs, "on take" alternate days and weekends. One doctor has responsibility for continuity of care to patients in half the beds of the unit. On-call cover coincides with days on for the practice. Patients admitted "on take" remain the responsibility of the admitting team throughout their stay in hospital. Each

Cirencester, Glos GL7 1YX

D L BEALES, MRCP, MRCGP, general practitioner patient is carefully investigated, and there is full access to pathology and radiology services at the Memorial Hospital. One of the general practitioners has undergone special training in gastroscopy, and a consultant opinion in other specialties is readily obtainable. The consultant geriatrician attends the hospital and is available to give an opinion on any admission but does not play an executive role.

Weekly case conferences are held in which all those concerned in treatment meet, with patients and relatives often taking part in discussions of aims. Regular attenders are the sisters and nursing staff, together with occupational therapists, physiotherapists, and a social worker. Visitors may include home help organisers, the patient's own GP, the district nurse, the domiciliary occupational therapist, and the pharmacist. The advantage of having one doctor co-ordinating these multidisciplinary case conferences is that he is able to bring patients forward for discussion at the right time. One doctor, therefore, has an overall view of all the patients in his ward. It would be difficult for all the GPs in this area, now numbering 22, to look after their own patients in the hospital. The case conference system of review would then be immensely complicated, and not all general practitioners wish to take a special interest in the elderly. The emphasis is on rehabilitation, and a close relation exists with the staff responsible for general medical beds at the Memorial Hospital. Patients are transferred at an early stage if they require extended rehabilitation and resettlement. The senior house officer at the Memorial Hospital attends our case conferences. Since the full implementation of these policies our admission rate has increased by more than one-third (figure; table). Any patient discharged for follow-up in the Querns Day Hospital is delegated to another two-man GP team, who also hold regular multidisciplinary case conferences. Jones and Ramaiah have described a similar effective use of a day hospital co-ordinated by general practitioners. ${ }^{3}$

Numbers of admissions, discharges, and deaths of geriatric patients at Querns Hospital 1978-81

\begin{tabular}{lrrrrr}
\hline & & 1978 & 1979 & 1980 & 1981 \\
\hline Admissions & $\ldots$ & 280 & 304 & 282 & 466 \\
Discharges &.. & 197 & 206 & 221 & 341 \\
Deaths $\quad$. &. & 88 & 96 & 66 & 120 \\
& & & & &
\end{tabular}

\section{Discussion}

Participation by general practitioners can offer advantages over the traditional hospital-based, career-centred approach to staffing units. The links between general practitioners and the geriatric consultant make this hospital an ideal introduction to the concepts of geriatric care for doctors in GP vocational training schemes.

Our opinion is that most patients do not need the full facilities of the district general hospital; selected patients are transferred if necessary and prompt return ensured. The real advantage of this arrangement accrues from the presence of an active unit serving its own local population and concentrating its efforts on the team approach to rehabilitation and resettlement 
in the community. Relatives or appropriate support can be brought in at an early stage after admission, and the patient does not suffer separation from his "natural area." This may be a key factor in reducing the demand for long-stay or residential care. Thus there is an early dialogue between community and staff familiar with local resources and sources of help. Day visits and shared care with relatives for patients with stroke can be planned almost from the first day of admission. Evidence suggests that the long-term benefit of stroke rehabilitation in a specialised unit is lost with time. ${ }^{4}$ We think that part of this loss of effectiveness is the breaking of links between hospital and home and the time it takes for patients to reacclimatise when discharge comes. If relatives are actively concerned in the rehabilitation process and supported through their initial sense of shock and panic-often followed by mixed emotions of anger, guilt, and depression-the staff, relatives, and patients can work together. If there is a genuine need for residential care or long-term care then this will become apparent to the relatives, who may accept it more readily because they have been taken into the doctors' confidence. It is not then seen as abandonment, and relatives or the community can then work together positively. We think that we can most effectively prevent patients needing this very expensive form of care by concentrating rehabilitation and the range of health and support systems close to the patient and his community. This policy differs from the recommendations of the British Geriatric Society ${ }^{5}$ given in its answer to the Royal Commission on the National Health Service. ${ }^{6}$ The Society's suggestion was that an eventual target of half of district general hospital beds was appropriate for the elderly. Our experience seems to show that these poilcies can be made flexible and so take account of the natural boundaries of small communities. In our area there have been considerable gains from concentrating a comprehensive geriatric service co-ordinated by general practitioners with a special interest in the subject in a relatively small unit.

If the system described here has been applied successfully in other areas then it is probably opportune to consider its more general adoption throughout peripheral hospitals in the country. Apart from the benefit the elderly derive from closer participation with general practitioners, this enlarged range of practitioner activity would inevitably increase the scope of general practice. Furthermore, the problems besetting medical training in

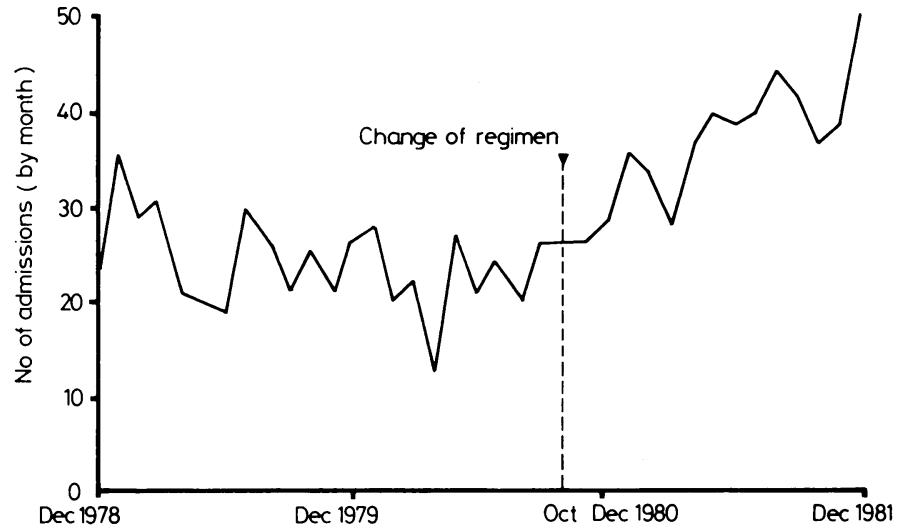

Admissions to Querns Geriatric Unit, December 1978 to December 1981.

hospitals at present might well be alleviated by the intervention of general practitioners and trainees in this sector of hospital care.

I thank Dr William Wright and Dr John Grove-White for their help in preparing this paper.

\section{References}

${ }^{1}$ Social Services Committee. Medical education with special reference to the number of doctors and the career structure in hospitals. Fourth report. London: HMSO, 1981. (Short Report.)

2 Department of Health and Social Security. Vocational training for general practice: the National Health Service (Vocational Training) Regulations 1979. Statutory Instrument 1644. London: HMSO, 1979.

3 Jones DT, Ramaiah RS. Day hospital care by general practitioners. $\mathrm{Br} \mathrm{Med}$ F $1981 ; 283$ :1441-2.

4 Garraway WM, Akhtar AJ, Hockey L, Prescott RJ. Management of acute stroke in the elderly. Br Med f 1980;281:827-9.

${ }^{5}$ British Geriatrics Society. Report. London: British Geriatrics Society, March 1981.

${ }^{6}$ Royal Commission on the National Health Service. Report. Cmnd 7615. London: HMSO, 1979.

(Accepted 2 March 1982)

\section{NHS London Weighting increased}

should not be supported just because he was a BMA member. It was more important to take note of what people stood for. The BMA had failed last time because of the success of the pressure groups and a lack of proper publicity. The Association should put up a slate of candidates, but it had to have a policy and greater publicity was needed, particularly in the $B M \mathcal{H}$. He would support candidates who favoured a more careful selection of medical students and the production of clinically mature doctors, looked after the interest of patients, and opposed the control of the GMC by the DHSS.

The junior doctors could have swamped the GMC if they had voted for each other, Dr Arnold Elliott claimed, but they had, he thought, voted for their professors and so a large number of academic staff were elected to the council.

In Dr John Noble's view the BMAsponsored candidates were not elected because the divisional and regional structures were weak. He criticised the single transferable vote system as an abomination and opposed the idea of BMA leaders standing for the GMC.

The minority groups, including the academic staff, had been successful, Dr Mary White said, because they had been better disciplined, whereas the BMA candidates had fought each other. There had not been enough publicity. She thought that the Council ought to be able to select more than 11 candidates; there ought to be a few extra ones for the Council to use as it thought fit.

The chairman of the GMC Working Group, Dr Brian Lewis, pointed out that if the BMA leaders did not stand then the leaders of other organisations would get on the GMC. The important thing was to educate members in the use of the single transferable vote system.

The Council agreed to recommend the sponsorship scheme to the Representative Body for approval.
Agreement has been reached on London Weighting allowances in the NHS for 1981, backdated to 1 July 1981 .

$\begin{array}{ccc} & \begin{array}{c}\text { Non resident } \\ \text { staff } \\ \text { London zone }\end{array} & \begin{array}{c}\text { Resident } \\ \text { staff }\end{array} \\ \begin{array}{ccc}£ 22 \text { (from } \\ £ 679)\end{array} & \begin{array}{c}£ 200 \text { (from } \\ £ 189 \text { ) }\end{array} \\ \begin{array}{ccc}\text { Extraterritorially } \\ \text { managed and } \\ \text { contiguous units }\end{array} & \begin{array}{c}£ 527 \text { (no } \\ \text { change) }\end{array} & \begin{array}{c}£ 147 \text { (no } \\ \text { change) }\end{array} \\ \text { Fringe zone } & £ 149 \text { (from } & £ 38 \text { (from } \\ & £ 141 \text { ) } & £ 36 \text { ) }\end{array}$

Doctors are entitled to claim their back pay and should contact their former employing authority if the authority has not contacted them. Negotiations are now taking place for the 1982 settlement due in July. 